\title{
A systematic literature review of the use and effectiveness of the Computer Assisted Rehabilitation Environment for research and rehabilitation as it relates to the wounded warrior
}

\author{
John-David Collins ${ }^{\mathrm{a}, *}$, Amanda Markham ${ }^{\mathrm{a}}$, Kathrine Service ${ }^{\mathrm{a}}$, Seth Reini ${ }^{\mathrm{a}}$, Erik Wolf ${ }^{\mathrm{b}}$ and \\ Pinata Sessoms ${ }^{\mathrm{a}}$

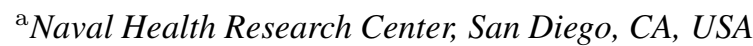 \\ ${ }^{\mathrm{b}}$ Walter Reed National Military Medical Center, Bethesda, MD, USA
}

Received 28 May 2013

Accepted 15 January 2014

\begin{abstract}
.
BACKGROUND: Several U.S. military treatment and research facilities employ a Computer Assisted Rehabilitation Environment (CAREN) [Motek Medical BV, Amsterdam, The Netherlands] for research and rehabilitation of complex injuries exhibited by Wounded Warriors. There has been little scientific evidence of the effectiveness of this type of system for rehabilitation.

OBJECTIVE: A systematic review of the literature was completed to determine what type of work has been performed on the CAREN and report findings of clinical significance.

METHODS: Specific terms were searched on electronic databases to include journal articles, abstracts, and peer-reviewed conference proceedings related to the CAREN.

RESULTS: Twenty-six publications were elicited that met our criteria. These were divided by their primary focus: rehabilitation, clinical research, and technical reports.

DISCUSSION: Results from published articles have determined that the system is a capable tool for both assessment and rehabilitation, but little has currently been published, particularly on patient populations.

CONCLUSION: More research needs to be performed to evaluate its effectiveness as a rehabilitation tool compared to other rehabilitation methods. It is expected that a system, such as the CAREN, will challenge patients multifactorially (e.g. physically and cognitively) and provide biofeedback while decreasing rehabilitation time and increasing effectiveness of treatment.
\end{abstract}

Keywords: CAREN, immersive virtual environment, warfighter, therapy

\footnotetext{
${ }^{*}$ Corresponding author: John-David Collins, 140 Sylvester Road, San Diego, CA 92106, USA. Tel.: +1 619553 3529; Fax: +1 619 767 4494; E-mail: johndavidcollins@gmail.com.
}

\section{Introduction}

As of Feburary 2014, more than 58,000 United States service members have been wounded in action while engaged as a part of the Global War on Terrorism (GWOT), beginning immediately after the September 


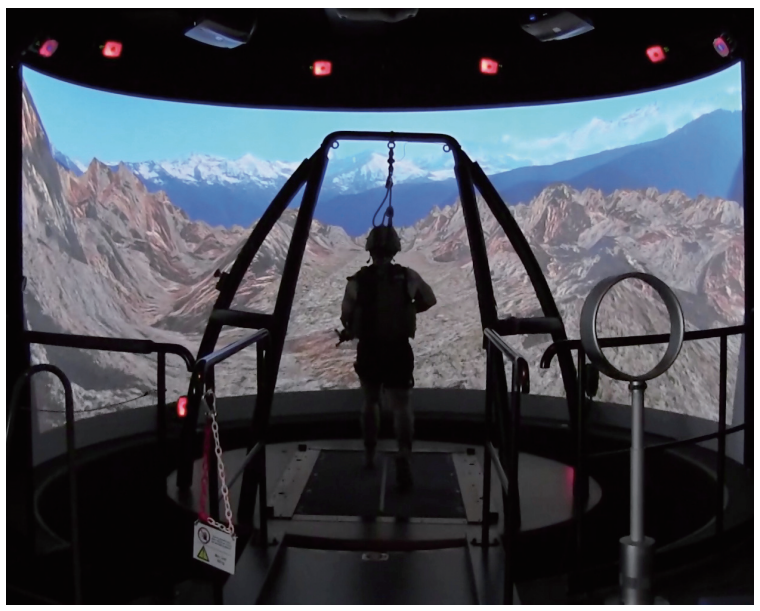

Fig. 1. Image of CAREN with military subject. (Colours are visible in the online version of the article; http://dx.doi.org/10.3233/WOR141927)

11, 2001 attacks on the World Trade Center in New York and the Pentagon in Washington, D.C. [1]. Many of these injuries were amputations, traumatic brain injuries (TBI), and other maladies requiring medical attention, care, and rehabilitation. The U.S. Department of Defense (DoD) has established several care centers to provide for those injured while in service of the U.S. military. Each establishment is equipped with stateof-the-art facilities and expert healthcare professionals trained to care for these service members. As of 2014, four DoD facilities employ a Computer Assisted Rehabilitation ENvironment (CAREN) [Motek Medical BV, Amsterdam, The Netherlands] for research and rehabilitation of complex injuries including musculoskeletal injury, amputation, vestibular disorders, and TBI. These sites are located at the National Intrepid Center of Excellence and the Walter Reed National Military Medical Center [2], both in Bethesda, $\mathrm{MD}$, at the Center for the Intrepid located at the San Antonio Military Medical Center in San Antonio, TX, and at the Naval Health Research Center in San Diego, CA [3].

The CAREN is an immersive virtual environment consisting of a forceplate-instrumented treadmill atop a 6 degree-of-freedom motion base platform. Surrounding this is a large screen (flat, curved panoramic, or dome) onto which a visual scene is projected and typically synchronized with the movements of the platform or the motion of the patient. A safety harness and optional side rails are in place to ensure patient comfort and safety. A three-dimensional motion capture system collects movement data while the patient or subject performs activities on the platform. D-
Flow, Motek's proprietary graphical based programming software, synchronizes and controls the varying data inputs and hardware for manipulation of the virtual environment (Fig. 1).

Capabilities and applications for this kind of virtual environment are seemingly bound only by the imagination of the CAREN operators, therapists, and surrounding team. Custom applications can be easily created and changed in real-time to suit the requirements set by the therapist and interests and ability of the patient. Visual flow data, treadmill, and platform movements may or may not be synchronized together, creating perceived balance and vestibular disturbances or assistance. Motion capture data from the subject on the CAREN can be used to drive the movements of the platform and visual data. Conversely, the visual flow data can drive the movement and speed of the platform and treadmill. Integration of data from the force platforms underfoot creates additional data inputs and methods for interaction. The CAREN was created for rehabilitation, research and sports purposes. It allows real-time feedback, clear and objective data, and gaming elements that are motivational while being in a controlled environment. The incredible clinical and research potential in a system like the CAREN are what make its higher price tag worthwhile. Patients can be safely encouraged to be less cautious in therapeutic activities in which they may be more timid out in realworld situations. Virtual scenarios can be designed to be reactive to the patients within the virtual environment, or designed to require the patients to react to the environment, or even a challenging combination of the two. This highly customizable capability of the system's components and overall function allows for individualized rehabilitation regimens based on the needs of the patient and the therapist's treatment methods and recommendations.

The first production grade CAREN system was installed in 2000. Since then, approximately 20 other systems have been installed worldwide. Due to the small number of systems in use, there has been little scientific evidence of the effectiveness of the CAREN for rehabilitation, though individual aspects of the system by themselves (e.g. virtual reality, biofeedback, and treadmill and balance training) have been shown to be effective rehabilitation training tools for different patient populations [4-9]. The true number and type of patients receiving treatment on the CAREN is not available since there is currently no ICD-9-CM code for this type of treatment. An estimate of the number of patients receiving therapy can only be based on 
what has been published. With the collective cost of installing, maintaining, and running a CAREN reaching over $\$ 1$ million U.S. dollars, there should be established evidence of the benefits of using a CAREN for clinical purposes. Evidence of the CAREN's effectiveness could be verified in continued objective reporting of outcomes for those using a CAREN for rehabilitation that have been published in peer-reviewed transactions and journals. Increased importance would be placed upon effective, improved, and novel methods in comparison to traditional rehabilitation. It is expected that a system of this design adds value by developing new care and rehabilitation methodologies, reducing time of rehabilitation, and potentially contributes to enabling service members to return to society and/or return to duty.

A systematic review of the literature was performed to determine what type of work has been performed on the CAREN and report findings of clinical significance. Since a number of CAREN systems are operated by DoD centers, it was also important to focus on the number of active-duty participants in these studies and what the primary focus of interest was for this population. This literature review highlights the benefits of the system and addresses knowledge gaps in order to identify what research is needed to determine the effectiveness of this tool for rehabilitation purposes. Since there have been relatively few publications involving this system, this paper aims to review all literature available concerning the CAREN, with a focus on those related to rehabilitation.

\section{Methods}

The literature search began with the National Center for Biotechnology Information search engine, PubMed [http://www.ncbi.nlm.nih.gov/pubmed]. Search terms included: CAREN, computer assisted rehabilitation environment, and virtual rehabilitation. Additionally, the Motek Medical website [http://www.motekmedical. com/publications/] was cross referenced. Dates began in 1999 based on the development of the CAREN system around that time, up to the date that this paper was written. After the initial literature was identified, abstracts, published IEEE peer-reviewed conference proceedings, and works cited from acquired literature were examined for additional papers that may have utilized a CAREN system. The inclusion criteria were those papers that utilized a CAREN as the main device for data collection or point of discussion within the work. Exclusion criteria were those papers which may have referenced but did not utilize the CAREN system in the work. Papers were divided by their primary focus: rehabilitation (including case and feasibility studies), clinical research with healthy and injured populations, and papers that describe the development and validation of the CAREN system and CARENfocused treatment and testing programs. Table 1 provides a summary of the papers. This paper focuses on the literature regarding rehabilitation, but will briefly reference the other articles as well.

\section{Results}

Thirty-one relevant articles were elicited from the search. Of these, 20 were published manuscripts and nine were conference proceedings. These papers were sorted into one of four categories based on their focus. Twelve articles were written with a rehabilitation focus; five compared an injured group with a noninjured control group; six were written as clinical studies with only healthy, non-injured populations and six discussed development or evaluation of the system. Eleven of the 31 CAREN-specific articles included military subject populations. Examining the body of work as a whole, a total of 270 subjects participated in some sort of reported activity on the CAREN (Table 2), though the same subject pool may have been utilized in multiple manuscripts. Of those, 107 (40\%) were from a patient population with injuries that included mild traumatic brain injury (mTBI), extremity trauma, stroke, and cerebral palsy. In total, $25 \%$ of the subjects were active-duty military, with $48 \%$ of military subjects having some sort of injury.

\subsection{Development and evaluation of the CAREN and CAREN-focused analysis programs}

The oldest article obtained in this literature review is an abstract published in 1999 from the annual meeting of Medicine Meets Virtual Reality [10]. That article discusses the development of the virtual reality (VR) system and the components that comprise a CAREN system, as well as the Dataflow software and forward and inverse dynamic computer simulations of motion. The purpose of the system was to originally develop a virtual interactive system using real-time biofeedback to create an efficient and effective rehabilitation training program utilizing functional training methods. Though mainly focused on balance behavior, that pa- 
Table 1

Summary of articles used in review of literature

\begin{tabular}{|c|c|c|c|c|c|c|}
\hline Authors & Title & Category & Year & \# of subjects & Rehab & Military \\
\hline Isaacson BM, Swanson TM, Pasquina PF & $\begin{array}{l}\text { The Use of a Computer-Assisted Research Environment for } \\
\text { Enhancing Wounded Warrior Rehabilitation Regimens }\end{array}$ & Intro & 2013 & 0 & & $\bar{X}$ \\
\hline Bartlett JL, Sessoms PH, Reini SA & $\begin{array}{l}\text { Strength Through Science: Using Virtual Technology to Ad- } \\
\text { vance the Warfighter }\end{array}$ & Intro & 2013 & 0 & $\mathrm{X}$ & $\mathrm{X}$ \\
\hline $\begin{array}{l}\text { Van der Eerden WJ, Otten E, May G, Even- } \\
\text { Zohar O }\end{array}$ & CAREN - Computer Assisted Rehabilitation Environment & $\begin{array}{l}\text { Development } \\
\text { \& Evaluation }\end{array}$ & 1999 & 0 & & \\
\hline Lees A, Vanrenterghem J, Barton G, Lake M & $\begin{array}{l}\text { Kinematic Response Characteristics of the CAREN Moving } \\
\text { Platform System for Use in Posture and Balance Research }\end{array}$ & $\begin{array}{l}\text { Development } \\
\text { \& Evaluation }\end{array}$ & 2007 & 0 & & \\
\hline Barton GJ, Vanrenterghem J, Lees A, Lake M & $\begin{array}{l}\text { A Method for Manipulating a Movable Platform's Axes of } \\
\text { Rotation: A Novel Use of the CAREN System }\end{array}$ & $\begin{array}{l}\text { Development } \\
\text { \& Evaluation }\end{array}$ & 2006 & 1 & $\mathrm{X}$ & \\
\hline El Makssoud HE, Richards CL, Comeau F & $\begin{array}{l}\text { Dynamic Control of a Moving Platform Using the CAREN } \\
\text { System to Optimize Walking in Virtual Reality Environments }\end{array}$ & $\begin{array}{l}\text { Development } \\
\& \text { Evaluation }\end{array}$ & 2009 & 0 & & \\
\hline $\begin{array}{l}\text { Fung J, Malouin F, McFadyen BJ, Comeau F, } \\
\text { Lamontagne A }\end{array}$ & Locomotor Rehabilitation in a Complex Virtual Environment & $\begin{array}{l}\text { Development } \\
\& \text { Evaluation }\end{array}$ & 2004 & NA & $\mathrm{X}$ & \\
\hline $\begin{array}{l}\text { Subramanian SK, Knaut LA, Beaudoin C, } \\
\text { McFayden BJ, Feldman AG, Levin MF }\end{array}$ & $\begin{array}{l}\text { Virtual Reality Environments for Rehabilitation of the Upper } \\
\text { Limb after Stroke }\end{array}$ & $\begin{array}{l}\text { Development } \\
\text { \& Evaluation }\end{array}$ & 2006 & 30 & & \\
\hline $\begin{array}{l}\text { De Groot IJM, Zohar OE, Haspels R, Van } \\
\text { Keeken H Otten E }\end{array}$ & CAREN (Computer Assisted Rehabilitation Environment): A & Development & 2003 & 1 & & \\
\hline van de Bogert AJ, Geijtenbeek T, Even-Zohar & A Real-Time System for Biomechanical Analysis of Human & $\begin{array}{l}\text { \& Evaluation } \\
\text { Development }\end{array}$ & 2013 & 12 & & \\
\hline O, Steenbrink F, Hardin EC & Movement and Muscle Function & \& Evaluation & & & & \\
\hline Everding VQ, Kruger SE & $\begin{array}{l}\text { Virtual Reality Enhanced Balance Training for Service Mem- } \\
\text { bers with Amputations }\end{array}$ & $\begin{array}{l}\text { Injured } \\
\text { Population }\end{array}$ & 2001 & 3 & $\mathrm{X}$ & $\mathrm{X}$ \\
\hline Kruger SE, Bell JC, Schnall BL & $\begin{array}{l}\text { Virtual Reality Enhanced Rehabilitation for a Service Mem- } \\
\text { ber with Bilateral Lower Extremity Amputations: A Case } \\
\text { Study }\end{array}$ & $\begin{array}{l}\text { Injured } \\
\text { Population }\end{array}$ & 2009 & 1 & $\mathrm{X}$ & $\mathrm{X}$ \\
\hline Kruger SE & $\begin{array}{l}\text { A Virtual Reality Approach to Gait Training in Service Mem- } \\
\text { bers with Lower Extremity Amputations }\end{array}$ & $\begin{array}{l}\text { Injured } \\
\text { Population }\end{array}$ & 2010 & 11 & $\mathrm{X}$ & $\mathrm{X}$ \\
\hline Darter BJ, Wilken JM & $\begin{array}{l}\text { Gait Training with Virtual Reality-Based Real-Time Feed- } \\
\text { back: Improving Gait Performance Following Transfemoral } \\
\text { Amputation }\end{array}$ & $\begin{array}{l}\text { Injured } \\
\text { Population }\end{array}$ & 2011 & 1 & $\mathrm{X}$ & $\mathrm{X}$ \\
\hline $\begin{array}{l}\text { Barton GL, Hawken MB, Foster RJ, Holmes } \\
\text { G, Butler PB }\end{array}$ & $\begin{array}{l}\text { Playing the Goblin Post Office Game Improves Movement } \\
\text { Control of the Core: A Case Study }\end{array}$ & $\begin{array}{l}\text { Injured } \\
\text { Population }\end{array}$ & 2011 & 1 & $\mathrm{X}$ & \\
\hline $\begin{array}{l}\text { Barton GJ, Hawken MB, Foster RJ, Holmes } \\
\text { G, Butler PB }\end{array}$ & $\begin{array}{l}\text { The Effects of Virtual Reality Game Training on Trunk to } \\
\text { Pelvis Coupling in a Child with Cerebral Palsy }\end{array}$ & $\begin{array}{l}\text { Injured } \\
\text { Population }\end{array}$ & 2013 & 1 & $\mathrm{X}$ & \\
\hline $\begin{array}{l}\text { Subramanian SK, Knaut LA, Beaudoin C, } \\
\text { Levin MF }\end{array}$ & $\begin{array}{l}\text { Enhanced Feedback During Training in Virtual Versus Real } \\
\text { World Environments }\end{array}$ & $\begin{array}{l}\text { Injured } \\
\text { Population }\end{array}$ & 2007 & 15 & & \\
\hline Rabago CA, Wilken JM & $\begin{array}{l}\text { Application of a Mild Traumatic Brain Injury Rehabilitation } \\
\text { Program in a Virtual Reality Environment: A Case Study }\end{array}$ & $\begin{array}{l}\text { Injured } \\
\text { Population }\end{array}$ & 2011 & 1 & $\mathrm{X}$ & $\mathrm{X}$ \\
\hline $\begin{array}{l}\text { Fung J, Richards CL, Malouin F, McFayden } \\
\text { BJ, Lamontagne A }\end{array}$ & $\begin{array}{l}\text { A Treadmill and Motion Coupled Virtual Reality System for } \\
\text { Gait Training Post-Stroke }\end{array}$ & $\begin{array}{l}\text { Injured } \\
\text { Population }\end{array}$ & 2006 & 3 & $\mathrm{X}$ & \\
\hline Gottshall, KR, Sessoms, PH, Bartlett, JL & $\begin{array}{l}\text { Vestibular Physical Therapy Intervention: Utilizing a Com- } \\
\text { puter Assisted Rehabilitation Environment in Lieu of Tradi- } \\
\text { tional Physical Therapy }\end{array}$ & $\begin{array}{l}\text { Injured } \\
\text { Population }\end{array}$ & 2012 & 4 & $\mathrm{X}$ & $\mathrm{X}$ \\
\hline Subramanian SK, Levin MF & $\begin{array}{l}\text { Viewing Medium Affects Arm Motor Performance in 3D Vir- } \\
\text { tual Environments }\end{array}$ & $\begin{array}{l}\text { Clinical: } \\
\text { Injured vs } \\
\text { Healthy }\end{array}$ & 2011 & 30 & & \\
\hline $\begin{array}{l}\text { Gates DH, Darter BJ, Dingwell JB, Wilken } \\
\text { JM }\end{array}$ & $\begin{array}{l}\text { Comparison of Walking Overground in a Computer Assisted } \\
\text { Rehabilitation Environment (CAREN) in Individuals With } \\
\text { and Without Transtibial Amputation }\end{array}$ & $\begin{array}{l}\text { Clinical: } \\
\text { Injured vs } \\
\text { Healthy }\end{array}$ & 2012 & 34 & & $\mathrm{X}$ \\
\hline $\begin{array}{l}\text { Kizony R, Levin MF, Hughey L, Perez C, } \\
\text { Fung J }\end{array}$ & $\begin{array}{l}\text { Cognitive Load and Dual Task Performance During Locomo- } \\
\text { tion Poststroke: A Feasibility Study Using a Functional Vir- } \\
\text { tual Environment }\end{array}$ & $\begin{array}{l}\text { Clinical: } \\
\text { Injured vs } \\
\text { Healthy }\end{array}$ & 2010 & 22 & & \\
\hline $\begin{array}{l}\text { Lamontagne A, Fung J, McFayden BJ, } \\
\text { Faubert J }\end{array}$ & $\begin{array}{l}\text { Modulation of Walking Speed by Changing Optic Flow in } \\
\text { Persons With Stroke }\end{array}$ & $\begin{array}{l}\text { Clinical: } \\
\text { Injured vs } \\
\text { Healthy }\end{array}$ & 2007 & 24 & & \\
\hline $\begin{array}{l}\text { Vrieling AH, van Keeken HG, Schoppen T, } \\
\text { Otten E, Hof AL, Halbertsma JP, Postema K }\end{array}$ & $\begin{array}{l}\text { Balance Control on a Moving Platform in Unilateral Lower } \\
\text { Limb Amputees }\end{array}$ & $\begin{array}{l}\text { Clinical: } \\
\text { Injured vs } \\
\text { Healthy }\end{array}$ & 2008 & 17 & & \\
\hline McAndrew PM, Dingwell JB, Wilken JM & $\begin{array}{l}\text { Walking Variability during Continuous Pseudorandom Oscil- } \\
\text { lations of the Support Surface and Visual Field }\end{array}$ & $\begin{array}{l}\text { Clinical: } \\
\text { Healthy }\end{array}$ & 2012 & 12 & & $\mathrm{X}$ \\
\hline $\begin{array}{l}\text { McAndrew Young PM, Wilken JM, Dingwell } \\
\text { JB }\end{array}$ & $\begin{array}{l}\text { Dynamic Margins of Stability During Human Walking in } \\
\text { Destabilizing Environments }\end{array}$ & $\begin{array}{l}\text { Clinical: } \\
\text { Healthy }\end{array}$ & 2012 & 12 & & $\mathrm{X}$ \\
\hline $\begin{array}{l}\text { Hak L, Houdijk H, Steenbrink F, Mert A, van } \\
\text { der Wurff P, Beek PJ, van Dieen JH }\end{array}$ & $\begin{array}{l}\text { Stepping Strategies for Regulating Gait Adaptability and Sta- } \\
\text { bility }\end{array}$ & $\begin{array}{l}\text { Clinical: } \\
\text { Healthy }\end{array}$ & 2013 & 10 & & \\
\hline $\begin{array}{l}\text { Hak L, Houdijk H, Steenbrink F, Mert A, van } \\
\text { der Wurff P, Beek PJ, van Dieen JH }\end{array}$ & $\begin{array}{l}\text { Speeding Up or Slowing Down?: Gait Adaptations to Pre- } \\
\text { serve Gait Stability in Response to Balance Perturbations }\end{array}$ & $\begin{array}{l}\text { Clinical: } \\
\text { Healthy }\end{array}$ & 2012 & 9 & & \\
\hline $\begin{array}{l}\text { Elion O, Bahat Y, Sela I, Siev-Ner I, Weiss P, } \\
\text { Karni A }\end{array}$ & $\begin{array}{l}\text { Postural Adjustments as an Acquired Motorskill: Delayed } \\
\text { Gains and Robust Retention After a Single Training Session } \\
\text { Within a Virtual Environment }\end{array}$ & $\begin{array}{l}\text { Clinical: } \\
\text { Healthy }\end{array}$ & 2008 & 7 & $\mathrm{X}$ & \\
\hline $\begin{array}{l}\text { Elion O, Bahat Y, Siev-Ner I, Sella I, Karni A, } \\
\text { Weiss PL }\end{array}$ & $\begin{array}{l}\text { No Transfer of Gains After a Single Training Session Within } \\
\text { a Virtual Environment to Fundamental Tests of Stability }\end{array}$ & $\begin{array}{l}\text { Clinical: } \\
\text { Healthy }\end{array}$ & 2009 & 16 & $\mathrm{X}$ & \\
\hline
\end{tabular}


Table 2

Population statistics, sorted by type of injury and number of military subjects for all articles cited in this review article

\begin{tabular}{lccccc}
\hline Group & Non-injured & Stroke & Amputee & mTBI & Other \\
\hline N & 163 & 61 & 38 & 5 & 3 \\
Military & 39 & 0 & 23 & 5 & 270 \\
\hline
\end{tabular}

${ }^{*}$ Non-injured are described as healthy, able-bodied individuals, some being demographically matched with their clinical counterparts in control studies. Stroke patients are those having experienced a stroke, some presenting with mild or moderate-to-severe hemiparesis. Amputees are subjects with unilateral or bilateral lower-limb amputation either transfemoral or transtibial. mTBI subjects are those having experienced some form of mild traumatic brain injury presenting with or without vestibular dysfunction. The Other group consists of one subject with cerebral palsy and one with fibula aplasia. Further, the number of active duty military subjects were broken down per population group as well as a total for all subjects within the literature review.

per also discussed the possibility of utilizing the virtual interactive system for sensory input and analysis of human motion. The development of the CAREN as a system that is easily manipulated in order to study multiple tasks by modifying the motion platform and treadmill in a variety of virtual scenarios is discussed by several authors [11-14]. Technical performance [10] and manipulation of axes of rotation $[12,13]$ of the motion platform have been described. Functionality of the CAREN's self paced treadmill, development of the system and virtual scenarios [14], as well as the software system, human body model (HBM), that computes joint kinematics and kinetics to analyze lower extremity function have also been described [15] in these development papers. Similarly, Subramanian et al. [16] described the development of a training environment in the CAREN for rehabilitation of the upper limb in patients with motor disorders due to stroke and other neurological conditions. De Groot et al. [17] published a case study, performing a whole body movement analysis within the CAREN on a patient with fibula aplasia walking with different footwear types. The authors note that the CAREN provided a safe, controlled environment suitable for studying the influences of shoes and orthoses worn by the patient. The CAREN has been in development for over 15 years, and these publications have shown that the system has progressed over time to something that is able to create realistic environments that are safe and suitable to collect therapeutic or research data. The work on the system has focused on subject interaction and real-time feedback, appropriate for cognitive and physical assessments or therapies.

\subsection{Injured population focused on rehabilitation techniques}

Ten articles have been written addressing the use of the CAREN as part of a rehabilitation program. In the majority of this work, the CAREN has been used to rehabilitate and train individuals with medical is- sues related to the lower extremity, with a large amount of the work addressing service members with amputation. Reports including biomechanics measurements indicate that the CAREN is a successful tool to rehabilitate and train individuals with lower extremity injuries over multi-week rehabilitation programs. Several studies [18-22] examined the use of the CAREN as an adjunct to conventional physical therapy for active duty persons with lower limb amputations to work on dynamic weight shifting and gait. They found improved performance over several weeks of training, though the type of improvements varied between studies. Studies by Kruger [19,20] reported increased selfselected walking velocities, decreased step width, improvements in overall stride symmetry, and ability to negotiate inclines and declines. Darter and Wilken [21] did not report the same improvements in temporal spatial parameters, but saw certain kinematic improvements (i.e. decreased total frontal-plane trunk excursion and better positioning of the pelvis over the prosthetic limb). They also reported sustained improvements during a three-week follow-up test session and decreased oxygen consumption of up to $23 \%$. Overall, therapy on the CAREN for persons with lower limb amputation is useful, but the number of subjects are low (total of 16 for all 4 studies) and there were no comparisons to persons undergoing traditional rehabilitation methods for the same period of time.

Other medical conditions, such as brain injuries and other vestibular disorders, have been treated and tested using the CAREN system. Past research reported that patients undergoing rehabilitation programs utilizing the CAREN showed improvements in debilitating symptoms such as vertigo and balance issues. In a case study by Rábago and Wilken [22] the CAREN was used as part of a twice weekly, three-week intervention for a service member with post-concussive disequilibrium and visual vertigo. Optokinetic stimulation and gaze stabilization challenges were used to improve visual vertigo symptoms while walking down a virtual city street, and weapon handling and targeting were 
introduced using an Iraq city scene. In both phases, therapists were able to increase the difficulty of the scenario by adding visual and physical tasks. Post assessment tests showed reduced visual vertigo and improved balance as well as improved executive function while performing dual-task tests. Another study by Gottshall et al. [23] used the CAREN in lieu of traditional vestibular physical therapy in an intervention involving service members with mild traumatic brain injury (mTBI). The six week, twelve-session therapy utilized CAREN scenarios that integrated visual and tactile inputs including weight and platform shifting, target shooting, and cognitive tasks while walking. Difficulty levels increased as each patient adapted to the scenarios. Traditional vestibular therapy tests were administered at three time points during the therapy. Posturography improved in three of four patients after six weeks. Other functional vestibular tests (functional gait assessment, dynamic visual acuity, gaze stabilization, dizziness handicap index, and balance confidence scores) improved among all four subjects by the end of the intervention. The ability to provide repetitive exposure in stimulating and realistic moving environments may have contributed to the improvements in these reported vestibular studies. Similar to the population of persons with lower limb amputation, there is potential that the CAREN could be an effective tool for vestibular physical therapy, but the small reported sample size means more research is needed before the effectiveness of the CAREN for treating persons with traumatic brain injury can be conclusively evaluated.

Other rehabilitation focused studies include the use of the CAREN to improve core strength and modulate coupling between the trunk and pelvis for children with cerebral palsy diplegia [24,25] and the use of different CAREN virtual environments to train stroke survivor patients to improve joint and trunk movements [26] and reacquisition of walking skills [27].

The review of these works concluded that all patient populations that underwent CAREN therapy showed improvements related to their rehabilitation focus (e.g. walking speed for persons with amputation, balance scores for persons with vestibular disorders, etc.). The breadth of different patient populations that have used the CAREN for treatment show the adaptable nature of this novel virtual reality system; but more extensive studies regarding the effectiveness of the CAREN are needed. These would examine whether results translate to functional improvements over time in varied populations.

\subsection{Healthy versus clinical control studies and clinical studies utilizing healthy populations}

\subsubsection{Clinical studies: Injured versus healthy controls}

Several studies have been conducted establishing the effectiveness of the CAREN as a tool for assessing performance of injured populations and providing a means of rehabilitation. Most notably, the injured populations examined have been persons who have experienced a stroke or some form of lower extremity amputation. In six studies found during the review, these populations were tested against a healthy, non-injured control population performing the same tasks. Of these six papers, two assessed the use of the CAREN against comparable testing devices. Subramanian et al. [28] assessed differences of use between two virtual environment media: a screen projection system utilizing the CAREN and a head mounted display system. The stroke patients and healthy controls performed an arm reaching task while instructed to "point as quickly and as close to the target as possible." Overall results indicated fewer errors and more precise movements when utilizing the screen projection in both groups. Gates et al. [29] compared walking over ground to walking on a treadmill in the CAREN with a group of transtibial amputees and a non-injured control group. Results indicated differences in step time and kinematics between the two environments for both subject populations though it was suggested that treadmill training in the virtual environment was similar enough to walking over ground and improvements would carry over.

In addition, three studies tested the use and feasibility of the CAREN and its ability to affect change in performance of post-stroke populations which were compared to uninjured, control groups. Kizony et al. [30] evaluated the CAREN as a dual-tasking tool for presenting physical and cognitive assignments (i.e. walking down a virtual grocery aisle while selecting specific items on a shelf). It was determined that use of this functional virtual environment was an effective tool that could be translated to activities of daily living. Fung et al. [27] tested the feasibility of the CAREN to promote re-acquisition of walking skills in two stroke patients compared with one healthy control. Subjects walked on a self-paced treadmill and difficulty increased with the addition of slopes and obstacles needing collision avoidance in the scene. Gait speed increased with practice in both patients, showing similar adaptation to the control subject. Similarly, Lamontagne et al. [31] evaluated the CAREN's ability to 
promote volitional changes in gait speed while controlling for adjustments in the optic flow (OF) presented on the screen. Stroke and control patients were able to voluntarily adjust walking speed when OF was manipulated and ultimately increase speed when presented with slower OF. The authors concluded that these techniques could be implemented into gait rehabilitation interventions to effectively improve gait speed.

Vrieling et al. [32] compared balance control on the CAREN in a group of persons with lower limb amputation to a healthy control group. Greater ground reaction force and center of pressure displacements were observed in the non-affected limb of persons with amputation compared to the control group during balance tasks as the CAREN platform moved. The authors determined that increased training of muscular strength and control during a complex balance task within the CAREN setting could be an effective tool for rehabilitation of those with lower-limb amputation.

\subsubsection{Clinical studies with healthy subjects}

Besides patient populations such as those with lower limb amputation or stroke groups, several research studies were found to utilize only healthy non-injured groups on the CAREN. Stepping strategies were measured in most of these CAREN related research studies [33-36]. These studies tested adaptations to visual or physical tasks or perturbations. These included perturbations such as the scene shifting on the screen, the platform shifting while walking, or the subjects being required to hit virtual targets to change gait patterns. Subjects were found to increase their step width and reduce step length, relative to no perturbation. For mediolateral oscillations, step time also increased [34]. Walking speed changes were variable, depending on type of perturbation - decreasing for increases in tasking while walking [35], but having no change in response to increased platform motions while walking [36]. Margins of stability were also calculated in these studies and suggest that identifying step to step changes may be useful in understanding how individuals control walking stability.

Other papers using healthy control groups studied the ability to acquire postural control skills after a single training session in a virtual environment [36,37]. Results were conflicting; with one study [37] concluding that a single training session was enough to trigger a learning process of balance and maintenance and the other study [36] stating that even though COP displacement decreased over successive balance assessments, there were no significant differences between the subjects who participated in the virtual environment balance training and those who did not.

\section{Discussion}

The ability to perform functional activities and analyze performance on the CAREN within a controlled environment provides a unique tool for researchers and therapists. Activities normally relegated to the outdoors, or in large spaces can be safely accomplished while on the CAREN. Using visual input, the CAREN can present multiple tasks simultaneously in conjunction with other physiologic or biomechanical measures that may be integrated and collected. Rehabilitation activities such as gait training, prosthetic adjustment, and balance training can all be performed on this system and have been effective in a limited number of studies involving relatively small populations. It is not yet clear if rehabilitation activities and techniques utilizing the CAREN provide more benefit compared to those of traditional methods, though patients report being more engaged in their therapy. More studies comparing CAREN therapy with traditional therapy methods should be performed.

The reported research has focused on several patient populations including persons with amputation, stroke, traumatic brain injury, vestibular dysfunction, and cerebral palsy. However, other areas of human performance research and rehabilitation such as pain management, auditory research, and dynamic activities which may or may not be related to specific sports movements have not yet been reported using the CAREN; limiting our knowledge of the effectiveness of the CAREN as an effective tool for widespread patient care.

There is a benefit that the CAREN incorporates many therapeutic (and has the potential to add many more) systems which have been shown to be effective for rehabilitation purposes (i.e. treadmill, virtual reality, and biofeedback abilities). The device also has use as a research tool for assessing responses to physical and cognitive perturbations in healthy controls. It is expected that the CAREN, with capabilities to challenge patients multifactorially (i.e. physically and cognitively), can decrease rehabilitation time and increase effectiveness of treatment.

The purpose of the CAREN systems in the DoD rehabilitation facilities is to provide a system that can be customized to patients' symptoms and treat the complex and polytraumatic injuries that these Wounded Warriors display, both cognitively and physically. It also aims to provide a tool that is engaging and challenges the patient in order to encourage patient adherence to therapy. This system is highly customizable 
and has great potential as an effective rehabilitation tool, as demonstrated in the positive outcomes for the patients in the papers discussed above. However, due to the relatively small numbers of patients using the system for therapy in the articles reviewed, more evidence is needed to justify the costs associated with installing, running, and maintaining a CAREN system.

Patients with a variety of disorders may benefit from CAREN-based therapies including those with psychological, neurological, musculoskeletal, and audiological disorders, among others. Because current literature regarding research and rehabilitation on the CAREN is limited, there are many areas in which future research can provide much more detail regarding the effectiveness of the CAREN. Continued research and evaluation of what types of patients (including disorder type, injury type, age, injury severity, etc.) would have the greatest benefit from CAREN-based therapies would be beneficial to the current literature base. For example, the literature in this area can benefit greatly from future investigations that examine longitudinal effects of CAREN-based therapies for treatment of psychological disorders as compared to traditional therapies for different age categories as well as for different psychological disorder types.

\section{Conclusion}

The purpose of the CAREN systems in the DoD rehabilitation facilities is to provide a system that can be customized to a patient's symptoms and treat the complex and polytraumatic injuries that Wounded Warriors display, both cognitively and physically. It also aims to provide a tool that is engaging and challenges the patient in order to encourage patient adherence to therapy. This system is highly customizable and has great potential as an effective rehabilitation tool, as demonstrated in the positive outcomes for the patients in the papers discussed above. However, due to the relatively small numbers of patients using the system for therapy in the articles reviewed, more evidence is needed to justify the costs associated with installing, running, and maintaining a CAREN system.

Literature on the effective use of the CAREN is lacking in many areas of research and treatment in areas for orthopaedic injury, hearing loss, and pain management. More research in these areas, as well as in areas that have been previously studied (gait and balance training, prosthetic adjustment, vestibular therapy) needs to be performed to evaluate the CAREN system's ef- fectiveness as a rehabilitation tool compared to other traditional rehabilitation methods. Studies or reports which discuss the limits of use and/or new methods by which this device can be used would also be beneficial to the growing number of sites which employ a CAREN system.

\section{References}

[1] GWOT Casualty Summary by Casualty type. Defense Manpower Data Center (DMDC). 2014. [cited 17JAN14]. Available from: https://www.dmdc.osd.mil/dcas/pages/report_sum _reason.xhtml.

[2] Isaacson, BM, Swanson, RM, Pasquina, PF. The use of a computer-assisted research [sic] environment (CAREN) for enhancing wounded warrior rehabilitation regimens. Journal of Spinal Cord Medicine 2013; 36(4): 296-299.

[3] Bartlett JL, Sessoms PH, Reini SA. Strength through science: using virtual technology to advance the Warfighter. Aviation, Space and Environmental Medicine. 2013; 84(2) 165-6.

[4] Dingwell JB, Davis BL, Frazier DM. Use of an instrumented treadmill for real-time gait symmetry evaluation and feedback in normal and trans-tibial amputee subjects. Prosthetics and orthotics international 1996; 20(2): 101-10.

[5] Geiger RA, Allen JB, O'Keefe J, Hicks RR. Balance and mobility following stroke: effects of physical therapy interventions with and without biofeedback/forceplate training. Physical therapy 2001; 81(4): 995-1005.

[6] Walker C, Brouwer BJ, Culham EG. Use of visual feedback in retraining balance following acute stroke. Physical therapy 2000; 80(9): 886-95.

[7] Shumway-Cook A, Anson D, Haller S. Postural sway biofeedback: its effect on reestablishing stance stability in hemiplegic patients. Archives of physical medicine and rehabilitation 1988; 69(6): 395-400.

[8] Davis BL, Ortolano M, Richards K, Redhed J, Kuznicki J, Sahgal V. Realtime visual feedback diminishes energy consumption of amputee subjects during treadmill locomotion. Journal of Prosthetics and Orthotics 2004; 16(2): 49-54.

[9] Yang YR, Tsai MP, Chuang TY, Sung WH, Wang RY. Virtual reality-based training improves community ambulation in individuals with stroke: A randomized controlled trial. Gait \& Posture 2008; 28: 201-6.

[10] Van der Eerden WJ, Otten E, May G, Even-Zohar O. CAREN - computer assisted rehabilitation environment. Medicine Meets Virtual Reality 1999: 373.

[11] Lees A, Vanrenterghem J, Barton G, Lake M. Kinematic response characteristics of the CAREN moving platform system for use in posture and balance research. Medical engineering and physics. 2007; 29: 629.

[12] Barton GJ, Vanrenterghem J, Lees A, Lake M. A method for manipulating a movable platform's axes of roation: A novel use of the CAREN system. Gait \& Posture. 2006; 24: 510.

[13] El Makssoud H, Richards CL, Comeau F. Dynamic control of a moving platform using the CAREN system to optimize walking in virtual reality environments. IEEE. 2009: 2384.

[14] Fung J, Malouin F, McFayden BJ, Comeau F, Lamontagne A, Chapdelaine S, et al. Locomotor rehabilitation in a complex virtual environment. Int'l Conference of the IEEE. 2004: 4859. 
[15] van den Bogert AJ, Geijtenbeek T, Even-Zohar O, Steenbrink F, Hardin EC. A real-time system for biomechanical analysis of human movement and muscle function. Medical and Biological Engineering \& Computing. 2013; 51: 1069-77.

[16] Subramanian SK, Knaut LA, Beaudoin C, McFadyen BJ, Feldman AG, Levin MF. Virtual reality environments for rehabilitation of the upper limb after stroke. Virtual Rehabilitation International Workshop. 2006: 18.

[17] De Groot IJM, Zohar OE, Haspels R, Van Keeken H, Otten E. CAREN (computer assisted rehabilitation environment): A novel way to improve shoe efficacy. Prosthet Orthot Int. 2003; 27: 158.

[18] Everding VQ, Kruger SE. Virtual reality enhanced balance training for service members with amputations. Int'l Conference on Virtual Rehabilitation, 2011.

[19] Kruger SE, Bell JC, Schnall BL. Virtual reality enhanced rehabilitation for a service member with bilateral lower extremity amputations: A case study. Int'l Conference on Virtual Rehabilitation. 2009: 126

[20] Kruger S. A virtual reality approach to gait training in service members with lower extremity amputations. Proc. $8^{\text {th }}$ Intl Conf. Disability, Virtual Reality \& Associated Technologies. Valparaiso, Chile. 31 Aug-2 Sept 2010.

[21] Darter BJ, Wilken JM. Gait training with virtual reality-based real-time feedback: improving gait performance following transfemoral amputation. Physical Therapy. 2011; 91(9): 598 1385-1394.

[22] Rábago CA, Wilken JM. Application of a mild traumatic brain injury rehabilitation program in a virtual realty [sic] environment: A case study. Journal of Neurologic Physical Therapy. 2011; 35: 185-193.

[23] Gottshall, KR, Sessoms, PH, Bartlett, JL. Vestibular physical therapy intervention: utilizing a computer assisted rehabilitation environment in lieu of traditional physical therapy. Engineering in Medicine and Biology Society (EMBC), 2012 Annual International Conference of the IEEE, Aug. 282012 Sept. 1 2012, pp. 6141-6144.

[24] Barton GJ, Hawken MB, Foster RJ, Holmes G, Butler PB. Playing the Goblin post office game improves movement control of the core: A case study. Int'l Conference on Virtual rehabilitation. 2011: 1 .

[25] Barton GJ, Hawken MB, Foster RJ, Holmes G, Butler PB. The effects of virtual reality game training on trunk to pelvis coupling in a child with cerebral palsy. Journal of NeuroEngineering and Rehabilitation. 2013; 10: 15.

[26] Subramanian SK, Knaut LA, Beaudoin C, Levin MF. Enhanced feedback during training in virtual versus real world environments. Virtual rehabilitation. 2007: 8.
[27] Fung J, Richards CL, Malouin F, McFayden BJ, Lamontagne A. A treadmill and motion coupled virtual reality system for gait training post-stroke. CyberPsychology \& Behavior. 2006; 9(2): 157-162.

[28] Subramanian SK, Levin MF. Viewing medium affects arm motor performance in 3D virtual environments. Neuroengineering and Rehabilitation. 2011; 8: 36.

[29] Gates DH, Darter BJ, Dingwell JB, Wilken JM. Comparison of walking overground and in a Computer Assisted Rehabilitation Environment (CAREN) in individuals with and without transtibial amputation. Neuroengineering and Rehabilitation. 2012; 9 .

[30] Kizony R, Levin MF, Hughey L, Perez C, Fung J. Cognitive load and dual-task performance during locomotion poststroke: A feasibility study using a functional virtual environment. Physical Therapy. 2010; 90: 252.

[31] Lamontagne A, Fung J, McFadyen BJ, Faubert J. Modulation of walking speed by changing optic flow in persons with stroke. Neuroengineering and Rehabilitation. 2007; 4: 22.

[32] Vrieling AH, van Keeken HG, Schoppen T, Otten E, Hof AL, Halbertsma JP, Postema K. Balance control on a moving platform in unilateral lower limb amputees. Gait \& Posture. 2008; 28: 222.

[33] McAndrew PM, Dingwell JB, Wilken JM. Walking variability during continuous pseudorandom oscillations of the support surface and visual field. Journal of Biomechanics. 2012; 43(8): 1470.

[34] McAndrew Young PM, Wilken JM, Dingwell JB. Dynamic margins of stability during human walking in destabilizing environments. Journal of Biomechanics. 2012; 45(6): 1053.

[35] Hak L, Houdijk H, Steenbrink F, Mert A, van der Wurff P, Beek PJ, van Dieen JH. Stepping strategies for regulating gait adaptability and stability. Journal of Biomechanics. 2013; 46: 905-911.

[36] Hak L, Houdijk H, Steenbrink F, Mert A, van der Wurff P, Beek PJ, van Dieen JH. Speeding up or slowing down? Gait adaptations to preserve gait stability in response to balance perturbations. Gait \& Posture. 2012; 36: 260.

[37] Elion O, Bahat Y, Sela I, Siev-Ner I, Weiss P, Karni A. Postural adjustments as an acquired motorskill: Delayed gains and robust retention after a single training session within a virtual environment. Virtual Rehabilitation. 2008: 50.

[38] Elion O, Bahat Y, Siev-Ner I, Sela I, Karni A, Weiss PL. No transfer of gains after a single training session within a virtual environment to fundamental tests of stability. Int'l Conference on Virtual Rehabilitation. 2009: 136. 